\title{
Insulin Transport across Capillaries Is Rate Limiting for Insulin Action in Dogs
}

Yeon J. Yang, Inez D. Hope, Marilyn Ader, and Richard N. Bergman

Department of Physiology and Biophysics, University of Southern California Medical School, Los Angeles, California 90033

\begin{abstract}
This study examined the relationship between transcapillary insulin transport and insulin action in vivo. During euglycemic clamps $(n=7)$ in normal conscious dogs we simultaneously measured plasma and thoracic duct lymph insulin and glucose utilization $\left(\boldsymbol{R}_{\mathrm{d}}\right)$. Clamps consisted of an activation phase with constant insulin infusion $(0.6 \mathrm{mU} / \mathrm{kg}$ per $\mathrm{min})$ and a deactivation phase. $\left[{ }^{14} \mathrm{C}\right]$ Inulin was infused as a passively transported control substance. While $\left[{ }^{14} \mathrm{C}\right]$ inulin reached an equilibrium between plasma and lymph, steady-state (ss) plasma insulin was higher than lymph $(P<0.05)$ and the ratio of 3:2 was maintained during basal, activation, and deactivation phases: $18 \pm 2$ vs. $12 \pm 1,51 \pm 2$ vs. $32 \pm 1$, and $18 \pm 3$ vs. $13 \pm 1 \mu \mathrm{U} / \mathrm{ml}$. In addition, it took longer for lymph insulin to reach ss than plasma insulin during activation and deactivation: $11 \pm 2$ vs. $31 \pm 5$ and $8 \pm 2$ vs. $32 \pm 6 \mathrm{~min}(P<0.02)$. $R_{\mathrm{d}}$ increased from $2.6 \pm 0.1$ to a ss of $6.6 \pm 0.4 \mathrm{mg} / \mathrm{kg}$ per $\mathrm{min}$ within $50 \pm 8 \mathrm{~min}$. There was a remarkable similarity in the dynamics of insulin in lymph and $\boldsymbol{R}_{\mathrm{d}}$ : the time to reach ss for $\boldsymbol{R}_{\mathrm{d}}$ was not different from lymph insulin $(P>0.1)$, and the relative increases of the two measurements were similar, $164 \pm 45 \%$ and $189 \pm 29 \%$ ( $P$ $>0.05)$. While there was only a modest correlation $(r=0.78, P$ $<0.01$ ) between $\boldsymbol{R}_{\mathrm{d}}$ and plasma insulin, the dynamic changes of lymph insulin and $R_{d}$ showed a strong correlation $(r=0.95, P$ $<0.01$ ). The intimate relationship between lymph insulin and $\boldsymbol{R}_{\mathrm{d}}$ suggests that the transcapillary insulin transport is primarily responsible for the delay in $R_{d}$. Thus, transcapillary transport may be rate limiting for insulin action, and if altered, it could be an important component of insulin resistance in obesity and diabetes mellitus.
\end{abstract}

\section{Introduction}

Insulin resistance is associated with non-insulin-dependent diabetes mellitus (NIDDM $\left.{ }^{1}\right)(1-3)$ as well as other common pathophysiologic states including obesity $(1,4-6)$. Understandably, much effort has been put forth to understand the specific defect(s) in the mechanism of insulin action responsible for resistance in obesity and NIDDM. After plasma insulin increases, a cascade of sequential steps is involved culminating in the enhancement of $\boldsymbol{R}_{\mathrm{d}}$, including ( $a$ ) transport of insulin

Address reprint requests to Dr. Bergman, Department of Physiology and Biophysics, USC Medical School, MMR1 10, 2025 Zonal Avenue, Los Angeles, CA 90033.

Received for publication 16 February 1989 and in revised form 5 July 1989.

1. Abbreviations used in this paper: Ginf, glucose infusion rate; $\mathrm{HGO}$, hepatic glucose output; NIDDM, non-insulin-dependent diabetes mellitus; $R_{\mathrm{d}}$, glucose utilization.

J. Clin. Invest.

(c) The American Society for Clinical Investigation, Inc.

$0021-9738 / 89 / 11 / 1620 / 09 \quad \$ 2.00$

Volume 84, November 1989, 1620-1628 from plasma to the cell surface $(7-10),(b)$ receptor binding $(11-13),(c)$ activation of tyrosine kinase $(14,15),(d)$ translocation of glucose transporters from the cell interior to the cell membrane (16-18) (and/or transporter activation), (e) glucose phosphorylation, and $(f)$ postphosphorylation metabolic events. While major efforts in the last decade have concentrated on postinsulin transport events, the process and significance of the movement of insulin from the plasma to the surface of the cell in determination of the time course and efficiency of insulin action has received surprisingly little attention.

When insulin is infused intravenously, attainment of steady-state $R_{\mathrm{d}}$ lags steady-state plasma insulin levels by several hours $(19,20)$. The delay in expression of insulin action may be attributed to the transport of insulin from the blood to insulin-sensitive cells, receptor binding and/or to postreceptor binding events. However, when insulin is added to cell cultures in vitro, no delays of similar length are observed $(11,21)$. Therefore, insulin transport to the interstitial medium bathing the insulin-sensitive cells emerges as a likely cause of the delay.

There is evidence supporting the concept that the movement of insulin into the interstitium, which precedes the binding of insulin to its receptor, is an important rate-determining step in insulin action. King and his colleagues $(8,9,22,23)$ have demonstrated that the movement of insulin across the capillary endothelial cell in vitro is rapid, and they have provided evidence that such transport is a receptor-mediated process. Rasio et al. $(10,24,25)$ reported a measurable delay between changes in plasma versus lymph insulin during intravenous glucose tolerance tests. Also, while they did not measure interstitial insulin directly, Sherwin and his colleagues $(20,26)$ used kinetic analysis to demonstrate a correlation between the calculated level of insulin in a compartment remote from plasma, and the rate of $R_{\mathrm{d}}$.

Thus, previous investigators have suggested that the movement of insulin from blood into the interstitium is an important determinant of the rate, if not the absolute magnitude of insulin action in vivo. Clearly, this insulin transport process could have important significance if it was altered in insulinresistant states, such as NIDDM. However, direct measurements of the so-called "remote" compartment from which insulin expresses its action have been very limited. Also, there have not previously been temporal comparisons of lymph insulin concentration and the rate of $R_{\mathrm{d}}$. To gather additional information we designed the present study to directly measure the time required for insulin transport to the interstitium as a necessary step in the exegesis of the time course and mechanism of insulin action. This was accomplished by measuring plasma and lymph insulin (which is derived from interstitial fluid) while simultaneously assessing whole body $\boldsymbol{R}_{\mathrm{d}}$ during euglycemic hyperinsulinemic clamps.

\section{Methods}

Materials. Porcine insulin was purchased from Sigma Chemical Co. (St. Louis, MO). Radioactive $\left[{ }^{14} \mathrm{C}\right]$ inulin was purchased from New 
England Nuclear (Boston, MA) and ICN Radiochemicals (Irvine, CA). Tritiated glucose was obtained from Amersham Corp. (Arlington, IL). Labeled ${ }^{125} \mathrm{I}$-insulin was kindly donated by Novo (Copenhagen, Denmark). Insulin antibody and canine insulin standard were purchased from Novo Laboratories.

Animals. Experiments were performed on chronically prepared, trained, male mongrel dogs (23-28 kg). Animals were housed in the University of Southern California Vivarium under controlled kennel conditions ( $12 \mathrm{~h}$ light, $12 \mathrm{~h}$ dark) and fed standard chow (25\% protein, 9\% fat, and 49\% carbohydrate: Wayne Dog Chow, Alfred Mills, Chicago, IL) once a day. Body temperature, hematocrit, and body weight were monitored regularly. Dogs were used for experiments only if judged healthy by general appearance and the above measurements. All the procedures were approved by the USC Institutional Animal Care and Use Committee.

Surgical procedure. Surgery was performed on five individual animals at least $5 \mathrm{~d}$ before the first experiment. The short interval between surgery and the first study was required to guarantee patency of chronic thoracic duct catheters. In two animals we were able to do two experiments; studies were separated by $4 \mathrm{~d}$.

The surgical procedure was as follows: after an overnight fast, dogs were anesthetized with Halothane and nitrous oxide. To aid in the identification of the thoracic duct, dogs were given 2-3 liters of saline during the first $90 \mathrm{~min}$ of the surgery to increase lymph flow. One catheter was inserted in the right internal jugular vein and advanced into the right atrium as described previously (27). After the longitudinal incision on the left side of the neck parallel to the internal jugular vein, the thoracic duct was identified beneath the junction of the internal jugular and subclavian veins. A Tygon catheter was introduced into the duct and secured. The external end of the thoracic duct catheter was connected to the end of a second cannula, itself secured in the left external jugular vein (28). This procedure established an external lymph/venous blood anastomosis, which effectively maintained continuous drainage of lymphatic flow to minimize clotting within the thoracic duct catheter between and during experiments when lymph collection was not required. After exteriorization, all catheters were placed in a small bag situated at the back of the neck and protected with a heavy denim collar.

Patency of the thoracic duct catheter was checked daily, and dogs were given 3,000 to 4,000 IU of heparin (Elkins-Sinn, Inc., Cherry Hill, $\mathrm{NJ}$ ) subcutaneously each morning (except on experiment days) and evening to prevent clot formation. Catheter location was confirmed at necropsy in all animals.

Experimental protocol. A total of seven euglycemic glucose clamp experiments are reported herein, in which plasma and lymph samples were collected. During the experiments dogs were in a conscious, relaxed state. Animals rested in a Pavlov sling and were given free access to water. Each 6-h clamp consisted of an activation phase during which a 3-h constant insulin infusion was administered, and a 3-h deactivation phase after termination of the infusion.

At 0730 , after an overnight fast, three intravenous intracatheters (Deseret Medical, Sandy, UT) were inserted: in the left cephalic vein for infusion of tracer $\left(\left[3-{ }^{3} \mathrm{H}\right]\right.$ glucose $)$ to assess glucose turnover, and in the left and right saphenous veins for infusions of porcine insulin and $20 \%$ dextrose (Kendall McGaw, Irvine, CA), respectively.

As previously recommended (29) a tracer quantity of $\left[3-{ }^{3} \mathrm{H}\right]$ glucose was added to glucose infused during clamps to avoid rapid dilution of the labeled glucose pool with unlabeled glucose. (If allowed, such dilution can result in underestimation of hepatic glucose output (HGO) and $R_{\mathrm{d}}$ [29]). Specific activity of exogenously infused glucose was 2.7 $\mu \mathrm{Ci} / \mathrm{g}$, calculated to match the mean basal plasma specific activity observed from 27 experiments previously done in our laboratory with the same tracer infusion rate.

To provide an extracellular marker with molecular size comparable to insulin (30), $\left[{ }^{14} \mathrm{C}\right]$ inulin was infused along with insulin. The inulin preparation we used was chosen to have a molecular weight $(5,000-$ 5,500 ) similar to insulin. In one experiment, cold inulin (Sigma Chemical Co.) was used instead of $\left[{ }^{14} \mathrm{C}\right]$ inulin.
At -120 min a primed infusion of $\left[3-{ }^{3} \mathrm{H}\right]$ glucose $(35 \mu \mathrm{Ci}$ bolus followed by $0.25 \mu \mathrm{Ci} / \mathrm{min}$ ) was initiated. After a 90 -min equilibration period, three basal samples were collected at $-30,-20$, and $-10 \mathrm{~min}$. Beginning at time 0 and continuing for $180 \mathrm{~min}$, insulin $(0.6 \mathrm{mU} / \mathrm{kg}$ per $\mathrm{min})$ and $\left[{ }^{14} \mathrm{C}\right]$ inulin $(0.09 \mu \mathrm{Ci} / \mathrm{min})$ were infused. Plasma glucose was clamped at basal by a variable glucose infusion according to the PACBERG algorithm (31). Right atrial blood (4 ml) and thoracic duct lymph $(1.5 \mathrm{ml})$ samples were taken simultaneously at 2,4 , and $7 \mathrm{~min}$, every $5 \mathrm{~min}$ between 10 and $30 \mathrm{~min}$, and every $10 \mathrm{~min}$ between 30 and $180 \mathrm{~min}$. At $180 \mathrm{~min}$, the insulin/inulin infusion was terminated, and the sampling schedule was repeated starting at $182 \mathrm{~min}$. A total of 49 samples from each site, including three basal samples, were collected.

Sampling of lymph was accomplished by letting it drip into microcentrifuge tubes beginning $30 \mathrm{~s}$ earlier and finishing $30 \mathrm{~s}$ later than blood sampling. The flow rate of thoracic duct lymph was generally $>1 \mathrm{ml} / \mathrm{min}$.

Blood and lymph samples were placed in tubes containing heparin and $\mathrm{NaF}$ and kept on ice until centrifugation. After separation, all samples were kept frozen at $-20^{\circ} \mathrm{C}$ for later assays.

Assays. Plasma and lymph glucose were assayed by the glucose oxidase technique on an automated analyzer (YSI, model 23A; Yellow Springs Instruments, Yellow Springs, $\mathrm{OH}$ ).

Insulin concentrations in plasma and lymph were measured in duplicate by radioimmunoassay using the dextran-charcoal separation technique (32). To confirm that insulin was measured similarly in plasma and lymph recovery studies were carried out over the physiologic range of plasma insulin concentration. Recoveries of added insulin by our assay were identical for plasma and lymph: in the concentration range of $20-90 \mu \mathrm{U} / \mathrm{ml}, 101 \pm 6 \%$ for plasma and $105 \pm 9 \%$ for lymph $(P>0.6)$. Plasma and lymph samples from each experiment were measured in the same assay.

For the determination of $\left[3-{ }^{3} \mathrm{H}\right]$ glucose in plasma and lymph, samples were deproteinized with $\mathrm{Zn}_{2} \mathrm{SO}_{4}$ and $\mathrm{BaOH}_{2}$ (33). The supernatant was then dried at $70^{\circ} \mathrm{C}$, redissolved in water, and counted in PCS scintillation fluid (Amersham) on a Beckman liquid scintillation counter with a two-channel dual-label automatic-quench correction program.

To measure $\left[{ }^{14} \mathrm{C}\right]$ inulin in plasma and lymph, $0.2 \mathrm{ml}$ of sample was mixed with $1.25 \mathrm{ml}$ tissue solubilizer (NCS; Amersham). After $30 \mathrm{~min}$ incubation at room temperature, samples were counted in $10 \mathrm{ml}$ of organic counting scintillant (OCS; Amersham) on a liquid scintillation counter as described above. For the single experiment in which cold inulin was used, assay was performed using the anthrone method (34).

Data analysis and calculations. Plasma glucose and tracer data were analyzed after optimal segments smoothing (35). $R_{\mathrm{d}}$ and HGO were calculated according to Steele's equation modified for nonsteady-state conditions (36). Modifications for labeled glucose infusion were performed according to Finegood et al. (29).

Steady-state values were calculated by averaging the data from the last hour of each phase of the clamp. The time to reach steady state was determined as the first point which attained a value within 2 SD from mean steady state in each experiment. The appearance time of insulin and inulin in lymph represents the time at which the concentration reached basal $+3 \mu \mathrm{U} / \mathrm{ml}$ and a non-zero values, respectively.

The rate constants $(k)$ of the decay data for plasma and lymph insulin, $\boldsymbol{R}_{\mathrm{d}}$ and $\mathrm{HGO}$ in the deactivation phase were determined by fitting data to mono-exponential curves using the MLAB modeling package (37) on a DEC-10 computer (Digital Electronics, Maynard, MA).

Statistical tests were performed with the Statfast program (38) on an IBM personal computer. All statistical comparisons were done using Student's paired and unpaired $t$ tests. Data are reported as mean $\pm S E$.

\section{Results}

Basal. Basal endogenous glucose production was $2.6 \pm 0.1$ $\mathrm{mg} / \mathrm{kg}$ per min. Interestingly, fasting basal glucose and insulin 
concentrations in lymph were not equal to glucose and insulin in plasma (Table I): glucose was slightly higher in lymph (102 \pm 2 vs. $96 \pm 2 \mathrm{mg} / \mathrm{dl} ; P<0.05)$ while insulin was considerably lower in lymph than in plasma $(12 \pm 1$ vs. $18 \pm 2 \mu \mathrm{U} / \mathrm{ml} ; P$ $<0.02$ ). There was no difference between plasma and lymph specific activity during the basal period $(P>0.4)$.

Clamp stability. Plasma glucose was successfully clamped at basal levels $(96 \pm 2 \mathrm{mg} / \mathrm{dl})$ with an average glucose infusion rate (Ginf) of $6.8 \pm 0.4 \mathrm{mg} / \mathrm{kg}$ per min at steady state (Figs. $1 A$ and $C$ ). The mean coefficient of variation for plasma glucose was $5 \pm 2 \%$. Furthermore, use of "spiked" glucose infusate minimized the variation in plasma specific activity observed during clamps (Fig. $1 \mathrm{~B}$ ). Specific activity fell slightly to a minimum of $82 \%$ of the basal value after $2 \mathrm{~h}$ of insulin, and increased to a value just $19 \%$ above the basal by the end of the study. This relative consistency of specific activity during the clamp study is in contrast to a precipitous fall of plasma specific activity by unlabeled glucose infusion during clamp experiments, which results in incomplete mixing of labeled glucose in the glucose pool (39).

The glucose concentrations in lymph $(99 \pm 1 \mathrm{mg} / \mathrm{dl})$ were similar to plasma $(97 \pm 1 \mathrm{mg} / \mathrm{dl})$ during the experiments $(P$ $>0.5$; Fig. $1 A$ ). At no time during the experiments was specific activity in lymph different from plasma $(P>0.05)$. Equivalence of plasma and lymph specific activity indicates that prelabeling the glucose infusate succeeded in achieving a homogenous extracellular glucose pool during glucose clamp experiments.

Inulin and insulin during the activation period. Inulin served as a reference molecule for transcapillary insulin transport since inulin, which has a similar molecular weight and size to insulin (30), is apparently transported across the capillary endothelium by diffusion alone (40). Following the initiation of the infusion (Fig. 2), $\left[{ }^{14} \mathrm{C}\right]$ inulin was first detected in lymph $6 \pm 1 \mathrm{~min}$ after its appearance in plasma, i.e., at $3 \pm 0.4$ min in plasma vs. $9 \pm 1 \mathrm{~min}$ in lymph. Although appearance of lymph inulin was delayed compared to plasma inulin, its dy-

Table I. Steady-state Values (Mean \pm SE) from Hyperinsulinemic Euglycemic Glucose Clamps $(n=7)$

\begin{tabular}{lccc}
\hline & & \multicolumn{2}{c}{ Glucose clamp period* } \\
\cline { 3 - 4 } & Basal & Activation & Deactivation \\
\hline Glucose $(m g / d l)$ & & & \\
Plasma & $96 \pm 2$ & $97 \pm 2$ & $100 \pm 1$ \\
Lymph & $102 \pm 2^{\ddagger}$ & $100 \pm 2$ & $99 \pm 1$ \\
Insulin $(\mu U / m l)$ & & & \\
Plasma & $18 \pm 2$ & $51 \pm 2^{\S}$ & $18 \pm 3$ \\
Lymph & $12 \pm 1^{\prime \prime}$ & $32 \pm 1^{\text {\$I }}$ & $13 \pm 1^{\prime \prime}$ \\
Glucose turnover rates $(m g / k g$ per min $)$ & \\
HGO" & $2.6 \pm 0.1$ & $0.2 \pm 0.1$ & $1.7 \pm 0.1$ \\
$R_{\mathrm{d}}{ }^{\prime \prime}$ & $2.6 \pm 0.1$ & $6.6 \pm 0.4$ & $2.2 \pm 0.1$ \\
Ginf & $0 \pm 0$ & $6.8 \pm 0.4$ & $0.4 \pm 0.1$ \\
& &
\end{tabular}

* The glucose clamp consisted of an activation phase, during which insulin was infused at $0.6 \mathrm{mU} / \mathrm{kg}$ per min, and a deactivation phase after termination of the infusion.

${ }^{\ddagger} P<0.05$, vs. plasma.

${ }^{8} P<0.02$, vs. basal.

" $P<0.02$, vs. plasma.

${ }^{\top} n=6$.

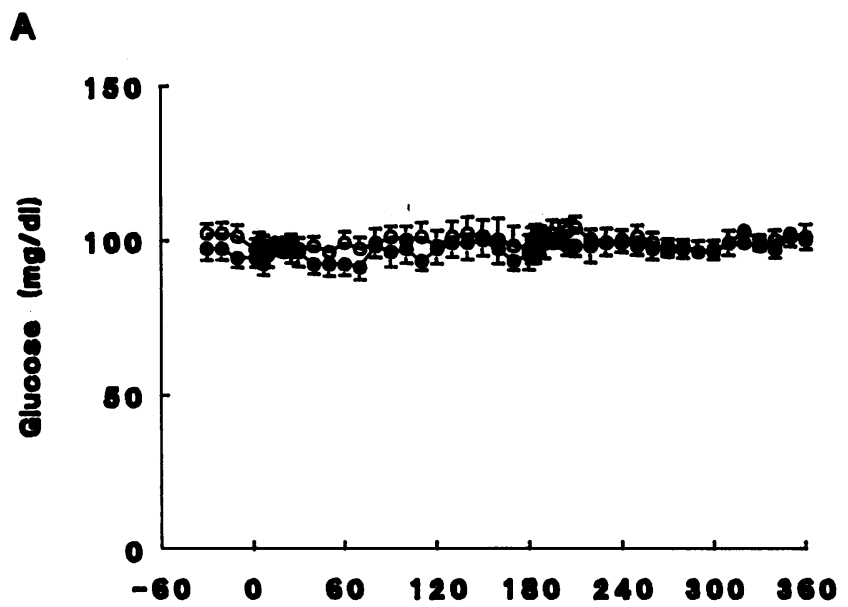

E
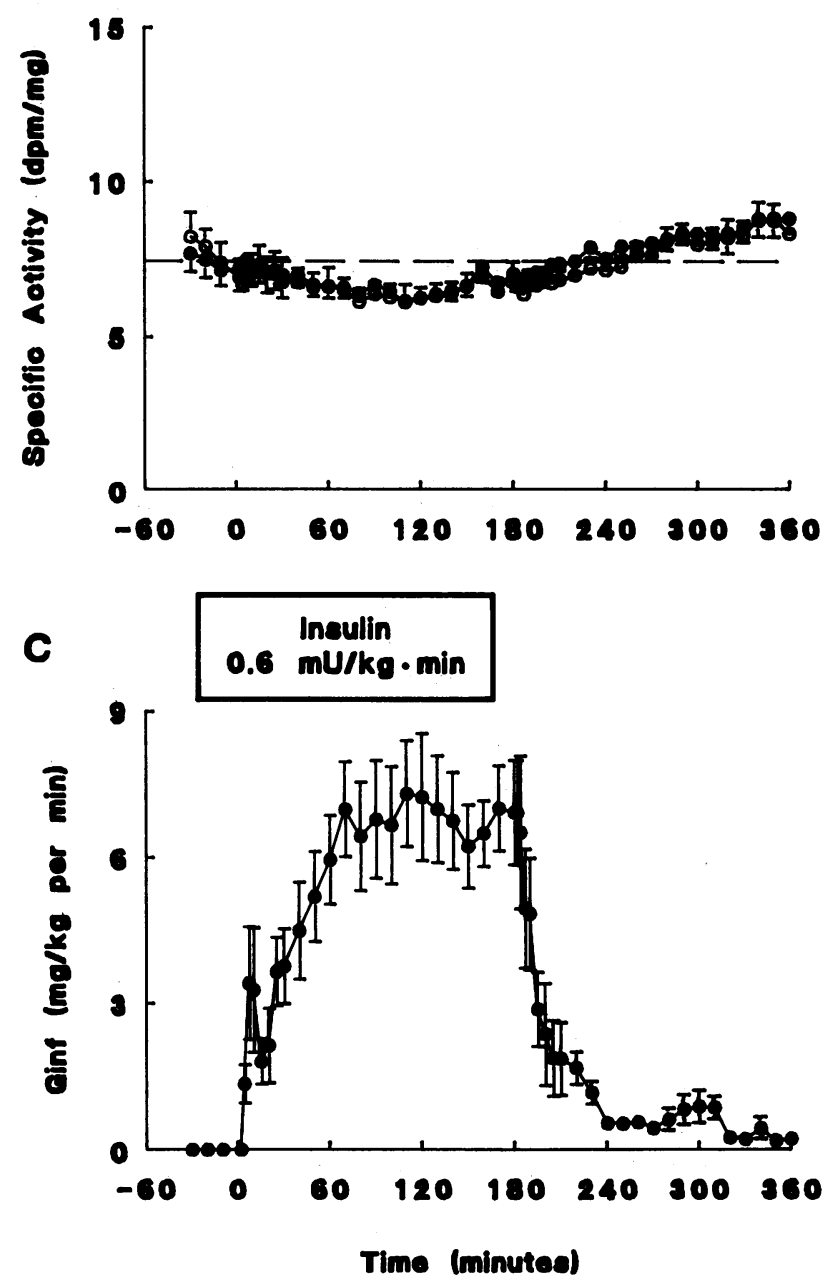

Figure 1. Hyperinsulinemic euglycemic glucose clamp results ( $n$ $=7$ ). Plasma glucose concentration was maintained at basal level with variable infusion of prelabeled glucose (Ginf). The closed and open circles in A and B represent the measurements in plasma and lymph, respectively. Broken line represents the basal specific activity.

namics in plasma and lymph were similar. Plasma inulin levels reached steady-state within $117 \pm 13 \mathrm{~min}$, lymph levels within $130 \pm 10 \mathrm{~min}$. Neither the steady-state concentrations $(1,621 \pm 37$ vs. $1,523 \pm 44 \mathrm{dpm} / \mathrm{ml})$ nor the time required to 


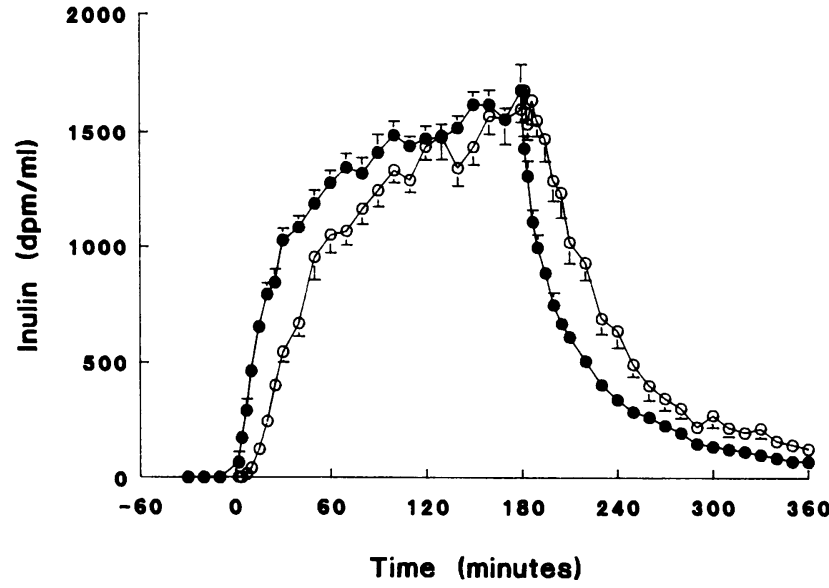

Figure 2. Plasma (closed circles) and lymph (open circles) $\left[{ }^{14} \mathrm{C}\right]$ inulin concentrations during systemic infusion $(0.09 \mu \mathrm{Ci} / \mathrm{min} ; 0-180 \mathrm{~min})$ and for the subsequent $3 \mathrm{~h}$ after the infusion was terminated $(n=6)$. The experiment in which cold inulin was infused was not included in this figure.

attain the steady-state were statistically different between plasma and lymph. The increase in lymph inulin to a level equivalent to plasma by $3 \mathrm{~h}$ is consistent with an absence of dilution of the thoracic duct lymph by any large molecule-free filtrate, and is also consistent with the removal of inulin in the body occurring only from the plasma compartment, presumably via the kidneys (41).

Despite similarities in molecular size and weight, the dynamics of insulin distribution between plasma and lymph were entirely different from those of inulin. The first contrast was in terms of the relative (plasma/lymph) steady-state levels achieved during infusion (Fig. 3); while inulin in lymph at steady-state was equal to plasma inulin (Fig. 2), insulin levels in lymph at steady-state were much less than plasma insulin (Table I). Plasma insulin increased to $51 \pm 2 \mu \mathrm{U} / \mathrm{ml}$ but lymph insulin increased only to $32 \pm 1 \mu \mathrm{U} / \mathrm{ml}, 62 \pm 4 \%$ of the plasma level $(P<0.02)$. Thus, the concentration gradient between

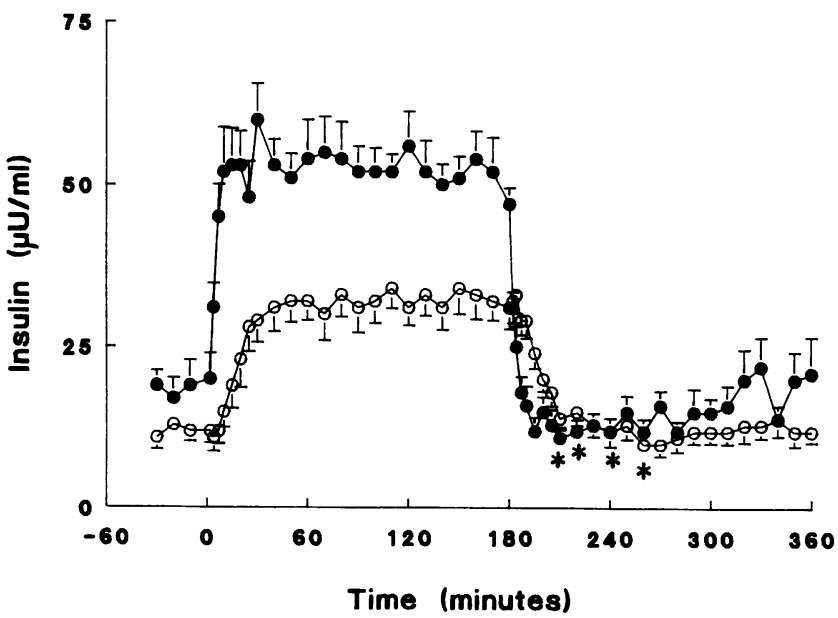

Figure 3. Plasma (closed circles) and lymph (open circles) insulin concentrations during the insulin infusion $(0.6 \mathrm{mU} / \mathrm{kg}$ per min, $0-180 \mathrm{~min}$ ) and for the $3 \mathrm{~h}$ after the cessation of the infusion $(n=7)$. Asterisks represent plasma insulin significantly different from basal level $(P<0.05)$. plasma and lymph insulin increased from $6 \pm 1$ to $19 \pm 1 \mu \mathrm{U} / \mathrm{ml}$ due to the insulin infusion. The second contrast between insulin and inulin was in terms of kinetics; while plasma and lymph inulin were similar, insulin kinetics were different in the two compartments. Lymph insulin level was elevated within $12 \pm 1 \mathrm{~min}$ following elevation of the plasma insulin level, and the time required for lymph insulin to attain steady state $(31 \pm 5 \mathrm{~min})$ was nearly three times longer than that required for the attainment of steady-state in plasma $(11 \pm 2 \mathrm{~min}$; $P<0.02$; Table II).

Inulin and insulin during deactivation period. At the termination of the combined infusion at $180 \mathrm{~min}$, inulin in plasma and lymph declined in a pattern which was virtually a mirror image of the increase in inulin during the initial $180 \mathrm{~min}$ (Fig. 2 ). As during the activation phase, there was a relatively constant absolute interval between plasma and lymph insulin, with plasma falling earlier than lymph. However, neither fluid compartment was completely cleared of inulin within the 3-h observation period. $74 \pm 7 \%$ of the amount of $\left[{ }^{14} \mathrm{C}\right]$ inulin infused was recovered from the urine during the experiments.

During deactivation insulin behaved very differently from inulin. During the final $3 \mathrm{~h}$, both plasma and lymph insulin returned to basal levels but again, lymph insulin was slower than insulin in plasma; plasma insulin returned to basal within $8 \pm 2 \mathrm{~min}$, while lymph insulin did not reach basal levels until $32 \pm 6 \mathrm{~min}$ after termination of the insulin infusion (Fig. 3 and Table II). The fractional disappearance rate of insulin from lymph was much slower than that in plasma $(k=0.07 \pm 0.01$ vs. $0.30 \pm 0.06 \mathrm{~min}^{-1} ; P<0.02$ ). Plasma insulin transiently dropped below basal between 210 and $260 \mathrm{~min}$ (Fig. 3), consistent with suppression of insulin secretion by exogenous insulin (42). However, the transient drop in plasma insulin was not reflected in lymph insulin, and given that plasma insulin was generally higher than lymph hormone, there was no significant difference between insulin levels in plasma and lymph during this period $(P>0.3)$. The concentration difference between plasma and lymph insulin was reestablished as plasma insulin returned to basal levels during the last $100 \mathrm{~min}$ of the deactivation phase. Thus, the ratio between steady-state plasma and lymph insulin levels also returned to $0.68 \pm 0.07$, similar to that during basal $(0.68 \pm 0.06)$ and the activation phase $(0.62 \pm 0.04 ; P>0.2)$.

Relationship between lymph insulin and glucose kinetics. To some extent, thoracic duct lymph may reflect interstitial fluid, as the thoracic duct is the route by which interstitial fluid reenters the blood. Because interstitial fluid can be considered

Table II. Time (Mean \pm SE) to Reach Steady State during the Activation and Deactivation Phases of the Hyperinsulinemic Euglycemic Clamp $(n=7)$

\begin{tabular}{llc}
\hline & Activation & Deactivation \\
\hline & \multicolumn{2}{c}{$\min$} \\
Plasma insulin & $11 \pm 2^{*}$ & $8 \pm 2^{\ddagger}$ \\
Lymph insulin & $31 \pm 5$ & $32 \pm 6$ \\
$R_{\mathrm{d}}^{\S}$ & $50 \pm 8$ & $45 \pm 14$ \\
HGO $^{\S}$ & $92 \pm 13^{*}$ & $27 \pm 4$
\end{tabular}

* $P<0.02$ vs. lymph insulin.

$\ddagger P<0.01$ vs. lymph insulin.

$\S n=6$. 
the milieu of insulin-responsive tissues, it is of interest to compare the time course of lymph insulin concentration with $R_{\mathrm{d}}$. Such a comparison could reveal the extent to which insulin movement from plasma to lymph is rate-determinant in insulin action.

As expected, insulin infusion into plasma increased $R_{\mathrm{d}}$ and suppressed HGO (Fig. 4). During activation, $\boldsymbol{R}_{\mathrm{d}}$ increased from basal $(2.6 \pm 0.1)$ to steady-state of $6.6 \pm 0.4 \mathrm{mg} / \mathrm{kg}$ per min by $3 \mathrm{~h}$ (Table I). Particularly striking is the tandem relationship between the relative increase in $R_{d}$ and the increase in lymph insulin. The relative increases in these measurements were similar: the extent to which $R_{\mathrm{d}}$ increased (164 $\left.\pm 45 \%\right)$ was the same as the relative increase in lymph insulin $(189 \pm 29 \% ; P$ $>0.05$; Fig. 5). More impressive is the comparative dynamics of lymph insulin and $R_{\mathrm{d}}: R_{\mathrm{d}}$ reached steady-state within $50 \pm 8$ min (Table II), only $19 \mathrm{~min}$ after attainment of steady-state lymph insulin; this difference in mean time to attain steadystate did not reach statistical significance $(P=0.2)$. Following termination of the insulin infusion, $R_{\mathrm{d}}$ returned to basal levels within $45 \pm 14 \mathrm{~min}$, which was not significantly different from the time for lymph insulin $(32 \pm 6 \mathrm{~min} ; P>0.1)$. The rate constant for the decay in $R_{\mathrm{d}}\left(0.08 \pm 0.02 \mathrm{~min}^{-1}\right)$ was similar to lymph insulin $\left(0.07 \pm 0.01 \mathrm{~min}^{-1} ; P>0.7\right)$. The close relationship between lymph insulin and whole-body $R_{\mathrm{d}}$ even during dynamic changes in lymph insulin may be considered as a plot between these variables (Fig. 6). While there was only a modest relationship between $R_{\mathrm{d}}$ and plasma insulin $(r=0.78 ; P$ $<0.01$; Fig. $6 A$ ), the relationship between $R_{\mathrm{d}}$ and lymph insulin was very strong at basal, steady state, and even during the dynamic activation and deactivation phases $(r=0.95 ; P$ $<0.01$; Fig. $6 \mathrm{~B}$ ). Thus, if lymph insulin can be hypothesized to be representative of interstitial insulin, Fig. 6 supports the concept that it is the transport to the interstitium that is ratelimiting in insulin action.

During insulin infusion, HGO was suppressed $89 \pm 4 \%$, to $0.2 \pm 0.1 \mathrm{mg} / \mathrm{kg}$ per min. Prelabeling the glucose infusate ameliorated underestimation of endogenous glucose production due to incomplete mixing within glucose pool during the clamp experiments. The estimates of HGO were not significantly below zero at any time (Fig. 4). Suppression of HGO took almost twice as long as $R_{\mathrm{d}}$ to reach steady state during the activation phase (92 $\pm 13 \mathrm{~min}$; Table II), $61 \mathrm{~min}$ after attain-

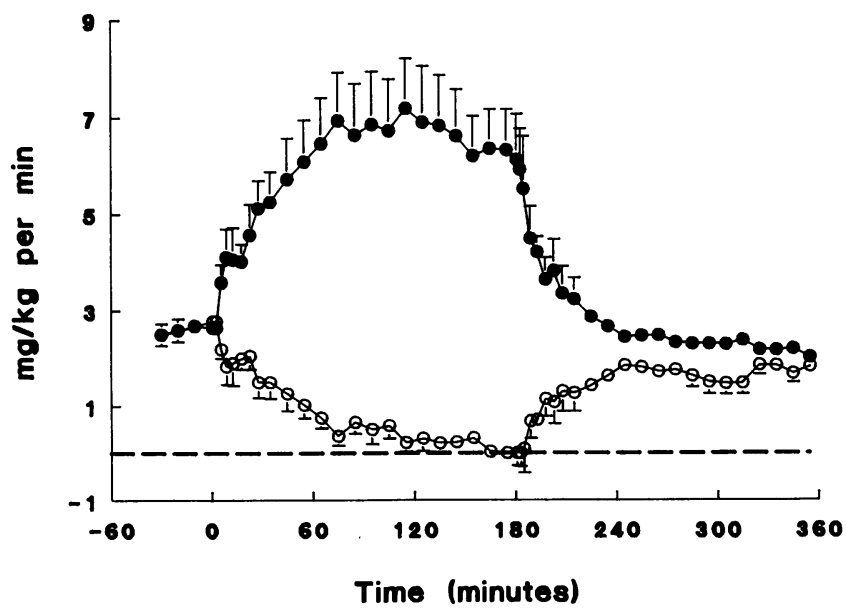

Figure 4. Glucose uptake ( $\boldsymbol{R}_{\mathrm{d}}$; closed circles) and hepatic glucose output (HGO; open circles) during clamps $(n=6)$.

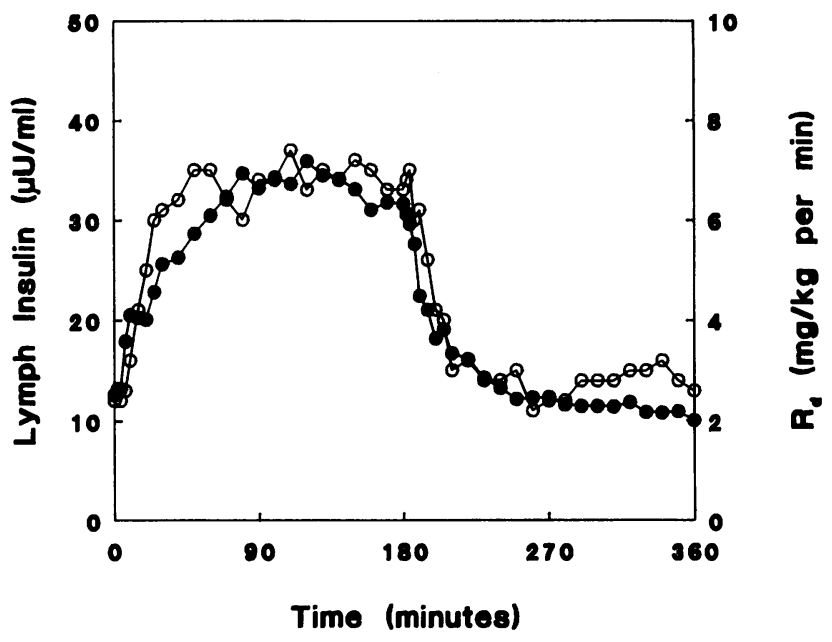

Figure 5. Average time course of lymph insulin (open circles) and $R_{\mathrm{d}}$ (closed circles; $n=6$ ). Not only the temporal relationship but also the relative increase due to insulin infusion were similar.

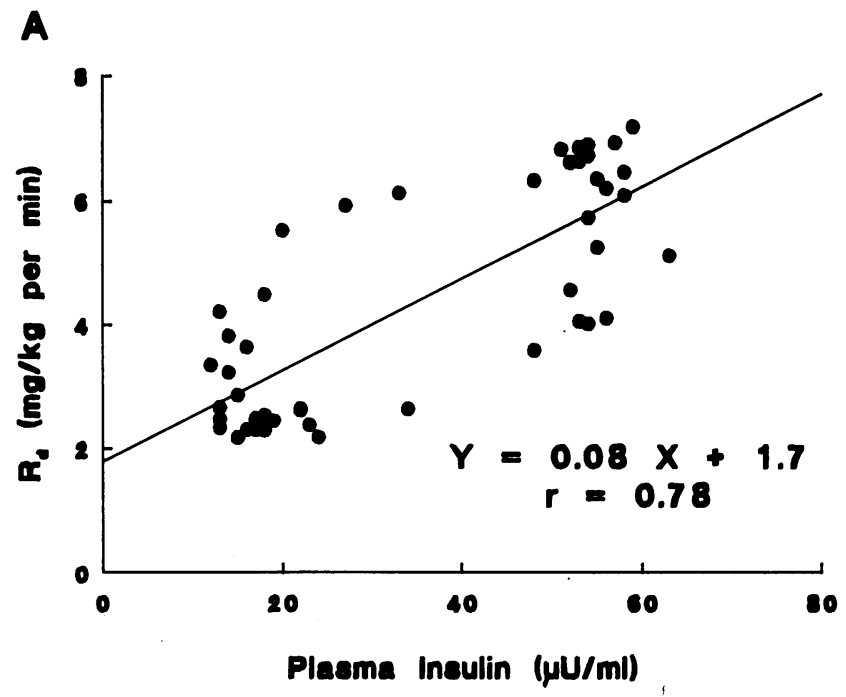

B

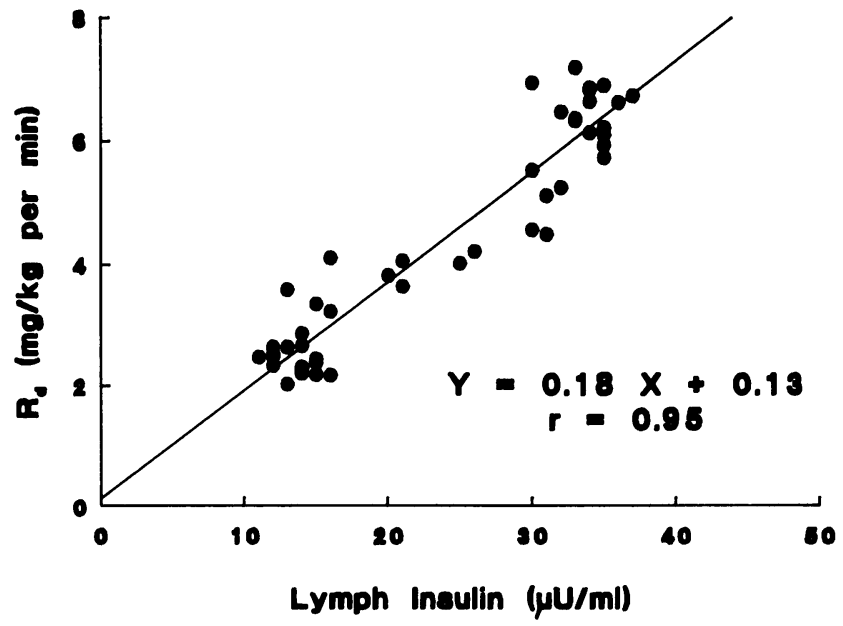

Figure 6. Relationship between the mean $R_{\mathrm{d}}$ and $(A)$ plasma insulin $(P<0.01)$ and $(B)$ lymph insulin $(P<0.01 ; n=6)$. 
ment of steady-state lymph insulin $(P<0.01$; Fig. 7). After termination of the insulin infusion, HGO did not return to basal levels within the 3-h observation period (Fig. 4 and Table I). Instead, HGO reached a sub-basal steady-state of $1.7 \pm 0.1$ $\mathrm{mg} / \mathrm{kg}$ per min within $27 \pm 4 \mathrm{~min}$. The fractional disappearance rate of the suppression of $\mathrm{HGO}$ was $0.08 \pm 0.03 \mathrm{~min}^{-1}$.

\section{Discussion}

A major effect of insulin to regulate the blood glucose concentration is the enhancement of glucose uptake by the peripheral tissues, of which muscle is quantitatively the most important $(43,44)$. In addition, insulin acts on peripheral tissues to regulate the supply of gluconeogenic substrates to the liver, and thus regulate endogenous glucose production (45). Because insulin binding is a rapid process (13), receptor binding can be expected to be in equilibrium with interstitial insulin concentration. Therefore, it is the insulin concentration in interstitial fluid in contact with the surface of insulin-sensitive cells which is the actual signal for cellular insulin-dependent events. From this perspective, it is important to characterize the process by which this essential hormone reaches insulin receptors, i.e., the movement of insulin across the capillary endothelium. The present study was designed to examine the in vivo kinetics of insulin distribution in order to determine the importance of insulin transport from plasma into the interstitium on the overall dynamics of insulin action. This was accomplished by simultaneously measuring plasma and lymph insulin as well as whole body $R_{\mathrm{d}}$ during euglycemic hyperinsulinemic clamps. Because of the possibility that anesthesia and/or somatostatin might alter blood flow distribution, and therefore lymph flow (46), we chose to estimate transcapillary distribution kinetics in conscious animals, without the use of the neuropeptide.

It is problematic to measure interstitial fluid insulin dynamically due to technical difficulties inherent in sampling interstitial fluid of sufficient quantity at a sampling frequency needed to study whole-body insulin kinetics. As an alternative, we followed the lead of Rasio and his colleagues, who sampled thoracic duct lymph as representative of interstitial fluid (10, 24, 25). Experimental evidence indicates that the composition and concentration of protein in lymph are similar to intersti-

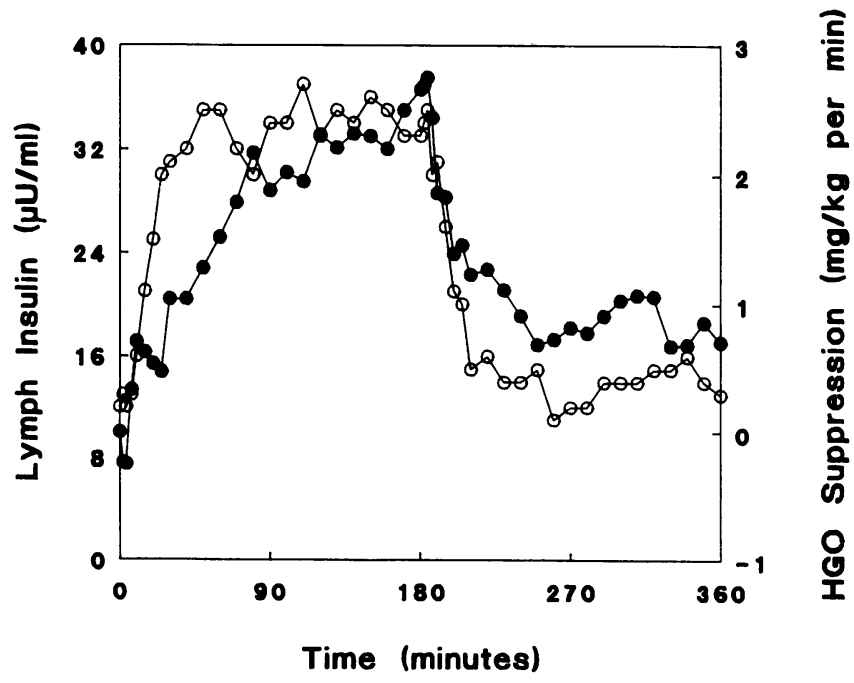

Figure 7. Average time course of lymph insulin (open circles) and suppression of HGO (closed circles; $n=6$ ). tial fluid $(47,48)$. The thoracic duct is the largest lymph vessel in the body and drains over two-thirds of the total body lymph. Unlike Rasio, we did our experiments in conscious animals, and we simultaneously measured glucose kinetics using the isotope dilution principle.

The present experiments represent the first report of the relationships between insulin in lymph and tracer-determined $R_{\mathrm{d}}$. As expected, the moment-to-moment correlation between plasma insulin and $R_{\mathrm{d}}$ was weak (Fig. $6 \mathrm{~A}$ ), confirming the concept originally introduced by Sherwin and his colleagues that a remote insulin compartment must be the signal for $R_{\mathrm{d}}$ $(20,26)$. In contrast, there was a striking similarity between lymph insulin and $R_{\mathrm{d}}$ during activation and deactivation phases of the euglycemic glucose clamps (Figs. 5 and $6 B$ ). Not only were these parameters correlated, but the proportional increase in $R_{\mathrm{d}}$ during the clamp was the same as that of lymph insulin. This proportionality between the two independently measured parameters is supportive of the concept that lymph insulin does indeed represent the signal that determines $R_{\mathrm{d}}$, and that lymph insulin represents interstitial insulin to which insulin-dependent cells are exposed. Of course, it is possible that this intimacy between lymph (i.e., interstitial) insulin and $R_{\mathrm{d}}$ is simply fortuitous. However, in more recent studies (data not shown) we have observed a similar proportionality between lymph insulin and insulin action during the intravenous glucose tolerance test (49). Thus, it seems likely that measuring insulin in lymph does provide a "window" into the remote compartment predicted by Sherwin and his colleagues, and supports the suggestion that Sherwin's remote insulin compartment is interstitial insulin.

In these studies, while we have assumed that thoracic duct lymph is representative of interstitial fluid in insulin-sensitive tissues, we are aware that under normal resting conditions the major portion of the thoracic duct lymph is derived from the abdominal viscera (50). These tissues are in general not sensitive to insulin, and insulin-increased $R_{\mathrm{d}}$ during euglycemic clamps occurs mainly at muscle tissues (44). However, it is reasonable that while we are not sampling muscle interstitial fluid, kinetics of insulin in the interstitium of abdominal viscera and muscle tissue are quite similar. Evidence for this similarity is the intimate relationship between lymph insulin and $R_{\mathrm{d}}$ (Figs. 5 and $6 \mathrm{~B}$ ). Also, we have obtained preliminary results indicating similarity between thoracic duct lymph insulin and lymph emanating directly from the forelimb during glucose clamps in dogs (unpublished). Thus, even though thoracic duct lymph may drain primarily internal organs, it may well be representative of lymph draining insulin-sensitive tissues. While this matter requires further study, at present it seems that thoracic duct lymph insulin is representative of interstitial insulin within insulin-dependent tissues.

Transport from plasma to interstitium is only the first of many steps in the cascade of insulin action. After transport, insulin must bind to target cell receptors, activate tyrosine kinase, generate putative second messengers and/or induce receptor autophosphorylation, and promote translocation (activation?) of intracellular glucose transporter proteins to the cell surface, ultimately leading to increased glucose uptake. However, because there is a substantial delay before appearance of insulin in lymph, and because there is a time-independent proportionality between lymph insulin and $R_{\mathrm{d}}$, we may conclude that it is the insulin transport process itself that is most responsible for the delay in insulin-stimulated $R_{\mathrm{d}}$. The present 
studies demonstrate that it is the transport of insulin from plasma into interstitium which is rate limiting for insulin action in vivo.

The delay in insulin action cannot be totally accounted for by transendothelial transport. Our data suggest a small delay between lymph insulin and $R_{\mathrm{d}}$ (Fig. 5 and Table II), although not consistently measurable. In the present studies, possible "modeling error" in $\boldsymbol{R}_{\mathrm{d}}$ associated with the Steele equation (36) was minimized by the attainment of near-constant glucose specific activity during glucose clamps by using labeled exogenous glucose infusion (29). However, while a finite delay between lymph insulin and $\boldsymbol{R}_{\mathrm{d}}$ was not readily demonstrable, current knowledge of insulin action insists that this delay occurs, reflecting the time necessary for insulin binding and postreceptor binding cellular events. This is consistent with achievement of maximal glucose transport rates within 5 to 10 min of insulin administration in isolated hepatocytes (17) and muscle cells (21). Nonetheless, it seems clear that the transport of insulin from the plasma to the interstitium remains the primary factor responsible for the delay between changes in plasma insulin and $\boldsymbol{R}_{\mathrm{d}}$.

In the deactivation phase, no measurable delay between lymph insulin and $R_{\mathrm{d}}$ kinetics was observed (Fig. 5). Not only was the time to reach steady-state for lymph insulin and $R_{\mathrm{d}}$ the same, but their fractional disappearance rates were also not different. Because plasma insulin declines rapidly at the cessation of the insulin infusion, the relationship between the rates of decline of interstitial insulin and $R_{\mathrm{d}}$ are independent of transport of insulin into the interstitial space. Therefore, while deactivation data cannot directly address the issue of transcapillary insulin transport, they are consistent with the concept that insulin transport to the interstitium is the rate-determining step.

It is also of interest to consider the relationship between insulin transport and the suppression of endogenous glucose production. The time course of mean suppression of HGO is plotted with that of mean lymph insulin in Fig. 7. HGO was even more delayed than peripheral $R_{\mathrm{d}}$ with respect to lymph insulin. This is remarkable because liver sinusoids have larger gaps than the capillary endothelium in the peripheral insulinsensitive tissues such as muscle and adipose tissue. Thus we would expect insulin to reach hepatic cells quicker than the peripheral tissues. Furthermore, after the termination of the insulin infusion, HGO did not recover to basal levels within the 3-h observation period, while lymph insulin returned to basal within $32 \mathrm{~min}$. One possible explanation for the result that HGO did not decline more quickly than $R_{\mathrm{d}}$ increased is that the primary effect of insulin to suppress HGO during clamps may be an indirect one to reduce gluconeogenic substrate flow (45). If so, it would be expected that HGO would decline at the same rate as, or even slower than $\boldsymbol{R}_{\mathrm{d}}$ would increase, as the effect of insulin on the peripheral tissues, i.e., to inhibit release of lactate, amino acids, or glycerol, could easily be slower than its effect to enhance glucose uptake. Alternatively, it is also possible that insulin may in fact act directly upon the liver to suppress HGO, but that induction and/or activation of key hepatic enzymes are responsible for the slower HGO dynamics.

To investigate the mechanism of insulin transport into the interstitium, we used $\left[{ }^{14} \mathrm{C}\right]$ inulin, with a molecular weight similar to insulin, as a reference molecule to reflect passive transcapillary transport (40). When inulin was infused intrave- nously, by $3 \mathrm{~h}$ an equilibrium was established between plasma and lymph inulin levels (Fig. 2). Such an equilibrium would not have been expected if inulin were transported by an energy-dependent process, or if there were net utilization of inulin by cells.

The steady-state relationships between plasma and lymph insulin were in sharp contrast to those of inulin. At basal, insulin concentrations in lymph were consistently lower than plasma, and a similarly positive 3:2 plasma/lymph insulin gradient was observed at hyperinsulinemic steady state (Fig. $3)$. In addition to the steady-state difference, there were nonsteady state kinetic differences between insulin and $\left[{ }^{14} \mathrm{C}\right]$ inulin distribution. Insulin appeared in lymph more slowly than inulin: after initiation of the infusion of both compounds, insulin increased in lymph 12 min after plasma, while lymph inulin increased but 6 min after plasma inulin. In addition, inulin reached steady state in lymph at approximately the same time as in plasma (Fig. 2), while insulin in lymph took longer to reach steady state than in plasma (Fig. 3). Thus, we observed a relative delay in insulin dynamics in lymph compared to inulin.

What may account for these differences between plasma and lymph insulin? Clearly, in steady-state, if lymph insulin is lower than plasma, one or more of the following possibilities must be true: (a) lymph is diluted with a volume of macromolecule-free filtrate, $(b)$ a fixed proportion of insulin is degraded by endothelial cells as the peptide crosses the capillary, or $(c)$ a significant mass of interstitial insulin is taken up by cells. Dilution of lymph is ruled out by the equality of plasma and lymph inulin at steady-state. Any macromolecule-free water dilution of lymph would dilute both molecules. Degradation of insulin by the capillary endothelial cells is not supported by the in vitro studies $(23,51)$, in which most of insulin taken up by the cultured endothelial cells was recovered intact in the medium.

The most plausible explanation for the concentration gradient between plasma and lymph insulin is a substantial cellular uptake of insulin from the interstitial compartment. Such a concept is consistent with the known fate of receptor-bound insulin: migration into coated pits, internalization, and subsequent lysosomal degradation $(52,53)$. These latter processes could account for the 3:2 concentration gradient at steady state observed for insulin, but lack of a gradient for inulin which presumably is not metabolized by cells. Furthermore, cellular uptake of insulin, not inulin, may affect the time course in lymph as well as the steady-state concentration. Intracellular insulin degradation will change free insulin concentration in lymph, which in turn may influence diffusion across the capillary wall. Lymph insulin levels may also be altered by retroendocytosis $(54,55)$, a process by which internalized intact hormone is recycled to the plasma membrane and extruded into the interstitial space; however the quantitative importance of this reverse process in vivo is unclear. Lastly, one must be cautious of the use of inulin as a reference molecule for transcapillary insulin diffusion. While similar in molecular weight and diffusionary indices $(32,40,56,57)$, their molecular composition is quite different (inulin is an inert polysaccharide, insulin a polypeptide), and thus their transport ultimately controlled by different biophysical factors.

It is important to reconcile our results with those of King and his colleagues (9), who presented evidence that the movement of insulin through capillary endothelial cells in vitro is a 
unidirectional, receptor-mediated process. The presence of insulin receptors in vascular endothelial cells has been demonstrated $(58,59)$. If we assume that diffusion of insulin and inulin are similar, then the proposal of King et al. demands that insulin transport should be faster than transport by diffusion alone (i.e., inulin transport). However, our results indicate a delay of lymph insulin to reach steady state, relative to that of plasma insulin, findings at first glance apparently inconsistent with the hypothesis of King. However, one must be cognizent of the fact that lymph insulin dynamics are not determined solely by transcapillary transport processes. Rather they may be markedly affected by the extent to which insulin is taken up by cells. Thus the mechanisms by which insulin is transported across the capillary endothelial boundary in vivo remain to be elucidated.

In conclusion, the present data suggests that transcapillary insulin transport determines the delay in insulin action during clamps. If this transendothelial transport process were altered in pathologic states, it could have a substantial effect on insulin action. Prager and his colleagues (5) have demonstrated variability in the rates of insulin activation and deactivation in obesity. While it has been proposed by Lillioja et al. (60) that this "rate defect" could be related to dispersion of insulin through the interstitium, it seems equally likely that a capillary insulin transport defect could be responsible. Clearly, modulation of the number and/or affinity of putative capillary transporters would have substantial effects on the dynamics as well as efficacy of insulin action in vivo. The present results provide additional support for focusing on transcapillary insulin transport as a possible factor in the pathogenesis of glucose intolerance, diabetes, and other diseases in which insulin resistance is manifest.

\section{Acknowledgments}

We wish to acknowledge Drs. Guillermo J. Valenzuela, Erlinda L. Kirkman, and Charles W. Hewitt for assistance in developing the surgical technique, and Elza Demirchyan, Debby Hollingshead and Myung-Sook Youn for technical assistance. We also thank Dr. Jang H. Youn for his helpful comments.

Yeon J. Yang was a predoctoral trainee supported by a National Institutes of Health (NIH) trainee grant (5T32GM08017). Marilyn Ader was a Postdoctoral Fellow of the American Diabetes Association. This work was supported by research grants from the NIH (DK-29867 and DK-27619).

\section{References}

1. Olefsky, J. M. 1981. Insulin resistance and insulin action: an in vitro and in vivo perspective. Diabetes. 30:148-162.

2. Kolterman, O. G., R. S. Gray, J. Griffin, J. Burstein, J. Insel, J. A. Scarlett, and J. M. Olefsky. 1981. Receptor and postreceptor defects contribute to the insulin resistance in non-insulin-dependent diabetes mellitus. J. Clin. Invest. 68:957-969.

3. Reaven, G. M., R. Bernstein, B. Davis, and J. M. Olefsky. 1976. Nonketotic diabetes mellitus: insulin deficiency or insulin resistance? Am. J. Med. 60:80-88.

4. Lillioja, S., and C. Bogardus. 1988. Obesity and insulin resistance: lessons learned from the Pima Indians. Diabetes. 4:517-540.

5. Prager, R., P. Wallace, and J. M. Olefsky. 1986. In vivo kinetics of insulin action on peripheral glucose disposal and hepatic glucose output in normal and obese subjects. J. Clin. Invest. 78:472-481.

6. Kolterman, O. G., J. Insel, M. Saekow, and J. M. Olefsky. 1980.
Mechanism of insulin resistance in human obesity. J. Clin. Invest. 65:1272-1284.

7. Bar, R. S., M. Boes, and A. Sandra. 1988. Vascular transport of insulin to rat cardiac muscle: central role of the capillary endothelium. J. Clin. Invest. 81:1225-1233.

8. King, G. L., S. M. Johnson, and I. Jialal. 1985. Processing and transport of insulin by vascular endothelial cells: effects of sulfonylureas on insulin receptors. Am. J. Med. 79:43-47.

9. King, G. L., and S. M. Johnson. 1985. Receptor-mediated transport of insulin across endothelial cells. Science (Wash. DC). 227:1583-1586.

10. Rasio, E. A., E. Mack, R. H. Egdahl, and M. G. Herrera. 1968. Passage of insulin and inulin across vascular membranes in the dog. Diabetes. 17:668-672.

11. Ciaraldi, T. P., and J. M. Olefsky. 1982. Kinetic relationships between insulin receptor binding and effects on glucose transport in isolated rat adipocytes. Biochemistry. 21:3475-3480.

12. Olefsky, J. M. 1976. The insulin receptor: its role in insulin resistance of obesity and diabetes. Diabetes. 25:1154-1162.

13. Kahn, C. R. 1976. Membrane receptors for hormones and neurotransmitters. J. Cell Biol. 70:261-286.

14. Kasuga, M., Y. Fujita-Yamaguchi, D. L. Blithe, and C. R. Kahn. 1983. Tyrosine-specific protein kinase activity is associated with the purified insulin receptor. Proc. Natl. Acad. Sci. USA. 80:21372141.

15. Stadtmauer, L. A., and O. Rosen. 1983. Phosphorylation of exogenous substrates by the insulin receptor-associated protein kinase. J. Biol. Chem. 258:6682-6685.

16. Ezaki, O., and T. Kono. 1982. Effects of temperature on basal and insulin-stimulated glucose transport activities in fat cells: further support for the translocation hypothesis of insulin action. J. Biol. Chem. 257:14306-14310.

17. Karnieli, E., M. J. Zarnowski, P. J. Hissin, I. A. Simpson, L. B. Salans, and S. W. Cushman. 1981. Insulin-stimulated translocation of glucose transport systems in the isolated rat adipose cell: time course, reversal, insulin concentration dependency, and relationship to glucose transport activity. J. Biol. Chem. 256:4772-4777.

18. Kono, T., F. W. Robinson, T. L. Blevins, and O. Ezaki. 1982. Evidence that translocation of the glucose transport activity is the major mechanism of insulin action on glucose transport in fat cells. $J$. Biol. Chem. 257:10942-10947.

19. Doberne, L., M. S. Greenfield, B. Schulz, and G. M. Reaven. 1981. Enhanced glucose utilization during prolonged glucose clamp studies. Diabetes. 30:829-835.

20. Sherwin, R. S., K. J. Kramer, J. D. Tobin, P. A. Insel, J. E. Liljenquist, M. Berman, and R. Andres. 1974. A model of the kinetics of insulin in man. J. Clin. Invest. 53:1481-1492.

21. Grimditch, G. K., R. J. Barnard, S. A. Kaplan, and E. Sternlicht. 1985. Insulin binding and glucose transport in rat skeletal muscle sarcolemmal vesicles. Am. J. Physiol. 249:E398-E408.

22. King, G. L., A. D. Goodman, S. Buzney, A. Moses, and C. R. Kahn. 1985. Receptors and growth-promoting effects of insulin and insulin-like growth factors on cells from bovine retinal capillaries and aorta. J. Clin. Invest. 75:1028-1036.

23. Jialal, I., G. L. King, S. Buchwald, C. R. Kahn, and M. Crettaz. 1984. Processing of insulin by bovine endothelial cells in culture. Diabetes. 33:794-800.

24. Rasio, E. A., G. J. Hill II, J. S. Soeldner, and M. G. Herrera. 1967. Effect of pancreatectomy on glucose tolerance and extracellular fluid insulin in the dog. Diabetes. 16:551-556.

25. Rasio, E. A., C. L. Hampers, J. S. Soeldner, and G. F. Cahill, Jr 1967. Diffusion of glucose, insulin, inulin, and Evans Blue protein into thoracic duct lymph of man. J. Clin. Invest. 46:903-910.

26. Insel, P. A., J. E. Liljenquist, J. D. Tobin, R. S. Sherwin, P. Watkins, R. Andres, and M. Berman. 1975. Insulin control of glucose metabolism in man. J. Clin. Invest. 55:1057-1066.

27. Finegood, D. T., G. Pacini, and R. N. Bergman. 1984. The insulin sensitivity index: correlation in dogs between values deter- 
mined from the intravenous glucose tolerance test and the euglycemic glucose clamp. Diabetes. 33:362-368.

28. Valenzuela, G., L. L. Woods, and R. A. Brace. 1986. Thoracic duct lymph flow in pregnant sheep and response to blood volume expansion. Am. J. Physiol. 250:R1095-R1098.

29. Finegood, D. T., R. N. Bergman, and M. Vranic. 1987. Estimation of endogenous glucose production during hyperinsulinemic euglycemic glucose clamps: comparison of unlabeled and labeled exogenous glucose infusates. Diabetes. 36:914-924.

30. Landis, E. M., and J. R. Pappenheimer. 1963. Exchange of substances through the capillary walls. In Handbook of Physiology. Vol 2. Circulation. P. Dow, editor. American Physiological Society, Washington, DC. 961-1034.

31. Pacini, G., D. T. Finegood, and R. N. Bergman. 1983. PACBERG: an adaptive program for controlling the blood sugar. Comp. Prog. Biomed. 16:13-20.

32. Herbert, V., K. Lau, C. W. Gottlieb, and S. J. Bleicher. 1965. Coated charcoal immunoassay of insulin. J. Clin. Endocrinol. Metab. 25:1375-1384.

33. Somogyi, M. 1945. Determination of blood sugar. J. Biol. Chem. 160:69-73.

34. Davidson, W. D., and M. A. Sackner. 1963. Simplification of the anthrone method for the determination of inulin in clearance studies. J. Lab. Clin. Med. 62:351-356.

35. Finegood, D. T., and R. N. Bergman. 1983. Optimal segments: a method for smoothing tracer data to calculate metabolic fluxes. Am. J. Physiol. 244:E472-E478.

36. Steele, R., R. S. Wall, R. C. DeBodo, and N. Altszuler. 1956. Measurement of size and turnover rate of body glucose pool by the isotope dilution method. Am. J. Physiol. 187:15-24.

37. MLAB: an on-line laboratory. 1983. National Institutes of Health, Bethesda, MD.

38. Statfast. 1985. Statsoft, Inc., Tulsa, OK.

39. Rizza, R. A., L. J. Mandarino, and J. E. Gerich. Dose-response characteristics for effects of insulin on production and utilization of glucose in man. Am. J. Physiol. 240:E630-E639.

40. Paaske, W. P., and P. Sejrsen. 1977. Transcapillary exchange of ${ }^{14} \mathrm{C}$-inulin by free diffusion in channels of fused vesicles. Acta Physiol. Scand. 100:437-445.

41. Gaudino, M. 1949. Kinetics of distribution of inulin between two body water compartments. Proc. Soc. Exp. Biol. Med. 70:672674.

42. Liljenquist, J. E., D. L. Horwitz, A. S. Jennings, J. Chiasson, U. Keller, and A. H. Rubenstein. 1978. Inhibition of insulin secretion by exogenous insulin in normal man as demonstrated by $\mathrm{C}$-peptide assay. Diabetes. 27:563-570.

43. DeFronzo, R. A., E. Jacot, E. Jequier, E. Maeder, J. Wahren, and J. P. Felber. 1981. The effect of insulin on the disposal of intravenous glucose: results from indirect calorimetry and hepatic and femoral venous catheterization. Diabetes. 30:1000-1007.

44. James, D. E., A. B. Jenkins, and E. W. Kraegen. 1985. Hetero- geneity of insulin action in individual muscles in vivo: euglycemic clamp studies in rats. Am. J. Physiol. 248:E567-E574.

45. Ader, M. 1987. Relative importance of direct versus indirect inhibition of hepatic glucose production by insulin. Diabetes. 36:182A. (Abstr.)

46. Nakabayashi, J., J. Sagara, N. Usukura, K. Yoshmitsu, T. Imamura, T. Seta, E. Yanase, M. Kawato, Y. Hiraiwa, S. Sakato, and R. Takeda. 1981. Effect of somatostatin on the flow rate and triglyceride levels of thoracic duct lymph in normal and vagotomized dogs. Diabetes. 30:440-445.

47. Renkin, E. M. 1979. Lymph as a measure of the composition of interstitial fluid. In Pulmonary Edema. A. P. Fishman and E. M. Renkin, editors. American Physiological Society, Bethesda, MD. 145-159.

48. Rutili, G., and K. Arfors. 1977. Protein concentration in interstitial and lymphatic fluids from the subcutaneous tissue. Acta Physiol. Scand. 99:1-8.

49. Yang, Y. J., I. D. Hope, and R. N. Bergman. 1989. Insulin transport across capillaries is the rate-limiting step for insulin action. Diabetes. 38:196A. (Abstr.)

50. Frank, B. W., and F. Kern, Jr. 1968. Intestinal and liver lymph and lymphatics. Gastroenterology. 55:408-422.

51. Dernovsek, K. D., R. S. Bar, B. H. Ginsberg, and M. N. Lioubin. 1984. Rapid transport of biologically intact insulin through cultured endothelial cells. J. Clin. Endocrinol. Metab. 58:761-763.

52. Marshall, S. 1985. Degradative processing of internalized insulin in isolated adipocytes. J. Biol. Chem. 260:13517-13523.

53. Duckworth, W. C. 1988. Insulin degradation: mechanisms, products, and significance. Endocrinol. Rev. 9:310-345.

54. Gliemann, J., and O. Sonne. 1978. Binding and receptor-mediated degradation of insulin in adipocytes. J. Biol. Chem. 253:78577863.

55. Levy, J. R., and J. M. Olefsky. 1987. The trafficking and processing of insulin and insulin receptors in cultured rat hepatocytes. Endocrinology 121:2075-2086.

56. Moller, U., P. Sejrsen, J. F. Hansen, and P. Hougaard. 1988. Determination of diffusion coefficients of insulin and insulin analogs in relation to physical and absorption properties. Diabetes. 37:163A. (Abstr.)

57. Radziuk, J., K. H. Norwich, and M. Vranic. Measurement and validation of nonsteady turnover rates with applications to the inulin and glucose systems. Fed. Proc. 33:1855-1864.

58. Bar, R. S., J. C. Hoak, and M. L. Peacock. 1978. Insulin receptors in human endothelial cells: identification and characterization. $J$. Clin. Endocrinol. Metab. 47:699-702.

59. Peacock, M. L., R. S. Bar, and J. C. Goldsmith. 1982. Interactions of insulin with bovine endothelium. Metab. Clin. Exp. 31:52-56.

60. Lillioja, S., A. A. Young, C. L. Cutler, J. L. Ivy, W. G. H. Abott, J. K. Zawadzki, H. Yki-Jarvinen, L. Christin, T. W. Secomb, and C. Bogardus. 1987. Skeletal muscle capillary density and fiber type are possible determinants of in vivo insulin resistance in man. J. Clin. Invest. 80:415-424. 